http://jmscr.igmpublication.org/home/ ISSN (e)-2347-176x ISSN (p) 2455-0450

crossref DOI: https://dx.doi.org/10.18535/jmscr/v8i11.80

Journal Of Medical Science And Clinical Research

\title{
A Study of Clinical Profile of Acute Kidney Injury in a Tertiary Hospital, Visakhapatnam
}

\author{
Authors \\ Dr Tammana Manasa ${ }^{1}$, Dr Y.G.S. Raju M.D², Dr A.L.A.Alekhya ${ }^{3}$ \\ ${ }^{1}$ Post graduate, Department of General Medicine \\ ${ }^{2}$ Professor, Department of General Medicine \\ ${ }^{3}$ Post graduate, Department of General Medicine
}

\begin{abstract}
Background and Objectives: Acute kidney injury is a common clinical condition encountered in our hospital. This study is an attempt to evaluate the clinical profile of acute kidney injury in 50 patients admitted to King George Hospital.

Method: This prospective study was done at King George hospital, over a period of 8 months. This study included fifty patients with clinical and laboratory evidence of acute kidney injury in patients admitted to our hospital.

Results: 32 male and 18 female patients with mean age of 48.01 years. Oliguria and vomiting were common presenting symptoms. Other common symptoms were fever, loss of appetite, jaundice and loose stools.

The etiological factors associated are malaria, septicemia and drug induced nephrotoxicity, Leptospirosis, Snakebite and Acute Gastroenteritis. Two patients had obstructive uropathy.

Conclusion: We observed oliguria and vomiting were common clinical features. Malaria was predominant etiological factor in our patients and falciparum malaria was more common than vivax malaria. However all these patients were treated conservatively. In our study, $90 \%$ of patients were survived. $74 \%$ of patients were treated conservatively and $26 \%$ of patients underwent hemodialysis.
\end{abstract}

\section{Introduction}

Acute kidney injury is a syndrome characterized by rapid(hours to weeks) decline in glomerular filtration rate (GFR) and retention of nitrogenous waste products such as blood urea nitrogen (BUN) and creatinine and perturbation of extra cellular fluid volume and electrolyte and acid base homeostasis ${ }^{1,2}$. AKI is a common clinical condition in hospitalized patients. ${ }^{3}$ The incidence of AKI in hospitalized patients is between $2 \%$ and $5 \%{ }^{4}$ The most common causes of AKI are; volume depletion, hypotension, aminoglycoside antibiotics and radiocontrast agents. Major surgery is also an important cause of AKI. Advanced age, liver diseases, underlying renal insufficiency and diabetes have been implicated as risk factors for the development of AKI. ${ }^{4}$

\section{Aims and Objectives}

AKI is a common clinical condition encountered in King George Hospital. This study is an attempt to analyse the common causes and clinical manifestations of acute kidney injury in fifty hospitalized patients at King George Hospital. 


\section{Materials and Methods}

This is a prospective study of patients with acute kidney injury admitted to King George Hospital between January 2020 to August 2020.

Study Protocol: Patients of both sexes above 18 years were included in this study. All these patients were studied with a detailed history, general physical examination, systemic examination and investigated as per the proforma.

All the patients were followed up till the time of discharge.

\section{Selection Criteria}

\section{A). Inclusion Criteria}

All inpatients aged $>18$ years with clinical and / or biochemical evidence of acute renal failure.

\section{B). Exclusion Criteria}

- Patients with pre-existing chronic renal failure or chronic renal disease.

- Patients aged below 18years.

\section{Results and Analysis}

Out of 50 cases studied, 32(64\%) patient were males and 18(36\%) were females.

Out of 50 cases, 46(92\%) patients had vomiting, $40(80 \%)$ had oliguria, 36(72\%) patients had history of fatigue. Fever was seen in $35(70 \%)$ cases and $16(32 \%)$ patient had loose stools.

\section{SIGNS AND SYMPTOMS}

\begin{tabular}{|l|c|c|}
\hline \multicolumn{1}{|c|}{ Symptoms and Signs } & Number & Percentage \\
\hline Vomiting & 46 & 92.0 \\
\hline Oliguria & 40 & 80.00 \\
\hline Fatigue & 36 & 72.0 \\
\hline Fever & 35 & 70.00 \\
\hline Loose stools & 16 & 32.0 \\
\hline Odema & 14 & 28.0 \\
\hline Jaundice & 12 & 24.0 \\
\hline
\end{tabular}

Out of 50 patients, 6(12\%) had history of nephrotoxic drug intake. Out of 50 patients, 6 (12\%) patients had history of diabetes mellitus and $6(12 \%)$ patients had hypertension.
Out of 50 cases, Renal AKI was seen in 38(76\%) patients, 10(20\%) patients had prerenal AKI and $2(4 \%)$ had post renal AKI.

\section{Types of AKI}

\begin{tabular}{|l|c|c|}
\hline \multicolumn{1}{|c|}{ Type } & Number & Percentage \\
\hline Renal & 38 & 76.0 \\
\hline Pre renal & 10 & 20.0 \\
\hline Post renal & 2 & 4.0 \\
\hline Total & 50 & 100.0 \\
\hline
\end{tabular}

Out of 50 cases studied, 10 patients had prerenal AKI. Out of which, 4(8\%) patients had acute GE,
$5(10 \%)$ patients had Malaria and one $(2 \%)$ patient had AKI following septicaemia. 
Patients with Pre-Renal AKI

\begin{tabular}{|c|c|c|}
\hline Diagnosis & Number & Percentage \\
\hline Acute GE & 4 & $8 \%$ \\
\hline Malaria & 5 & $10 \%$ \\
\hline Septicaemia & 1 & $2 \%$ \\
\hline
\end{tabular}

Out of 50 cases, 38 patients had renal cause. Out of which, Malaria was seen in 12 (24\%) patients, $6(12 \%)$ patients had nephrotoxic AKI, 6(12\%) patients had septicaemia, 2(4\%) had post infectious glomerulonephritis, 2(4\%) had snakebite and $1(2 \%)$ had Rhabdomyolysis. Acute gastroenteritis seen in $5(10 \%)$ of patients, CCF $1(2 \%)$.

\section{Patients with Renal AKI}

\begin{tabular}{|l|c|c|}
\hline \multicolumn{1}{|c|}{ Diagnosis } & Number & Percentage \\
\hline Acute GE & 5 & $10 \%$ \\
\hline CCF & 1 & $2 \%$ \\
\hline Drug induced & 3 & $6 \%$ \\
\hline Leptospirosis & 12 & $24 \%$ \\
\hline Malaria & 2 & $4 \%$ \\
\hline PIG & 1 & $2 \%$ \\
\hline Rhadomyolysis & 6 & $12 \%$ \\
\hline Septicaemia & 2 & $4 \%$ \\
\hline Snakebite & & \\
\hline
\end{tabular}

Among 50 cases, 37(74\%) patients were managed conservatively and 13(26\%) patients underwent hemodialysis. Among the patients managed conservatively $1(2 \%)$ patient died and among those who underwent hemodialysis $4(8 \%)$ patients died.

Out of 50 cases studied, 45(90\%) patients survived. Mortality was seen in $5(10 \%)$ patients. 4 patients had AKI following septicaemia and one patient died due to drug induced renal failure.

\section{Discussion}

In the present study, vomiting and oliguria were most common symptoms comprising of $92 \%$ and
$80 \%$ respectively. This finding is comparable with other studies done by Singhal AS et al., which showed that oliguria was seen in $85.2 \%$ of patients and that $80 \%$ of patients had vomiting. ${ }^{20}$ In the present study, fever was seen in $70 \%$ of patients. However, this symptom was not observed in other studies. This could be explained by higher incidence of AKI associated with infections like malaria, leptospirosis in the present study.

In the present study, about $2(4 \%)$ of the patients had obstructive uropathy. This was comparable to a study done by Singhal AS et al., about $5 \%$ of patients had obstructive uropathy. ${ }^{8}$ Hakim $\mathrm{Al}$ et 
al., in their study $9 \%$ of patients had AKI following bladder outlet obstruction.

In this present study good results were obtained with conservative management. One patient who died had septicaemia and respiratory failure. This was comparable to a study done by Hakim Al et al.

In the present study, 38(76\%) patients had AKI due to renal cause.

Majority of patients had malaria 12(24\%) with falciparum more common than vivax. This could be because; the study was done in a malaria endemic area. Other common presentations were septicaemia in $6(12 \%)$ patients, drug nephrotoxicity 6(12\%), leptospirosis 3(6\%), snakebite 2(4\%), acute gastro enteritis $5(10 \%)$,

Rhabdomyolysis $1(2 \%)$, congestive cardiac failure $1(2 \%)$ and post infectious glomerulonephritis was seen in 2(4\%) patients. Singhal AS et al., in their study found that malaria was the predominant cause of AKI involving about $46 \%$ of patients followed by snakebite $(20 \%)$ patients, acute GE $12 \%$ patients, septicaemia $12 \%$, drug nephrotoxicity $3 \%$ and acute gastroenteritis in $2 \%$ of patients. ${ }^{8}$

\section{Conclusion}

In this study 50 patients were studied prospectively admitted between August 2019 to August 2020. The clinical feature were studied. It was observed that clinical features were almost in accordance with studies conducted earlier. Oliguria and vomiting were still continuous to be the predominant symptoms in acute kidney injury. However we observed malaria was the predominant cause of acute kidney injury and these patients were recovered with conservative management and antimalarials. Other causes of renal failure in our study were similar to other studies like drug nephrotoxicity, acute gastroenteritis and septicemia. About $90 \%$ patients were survived. $74 \%$ of patients were treated conservatively and $26 \%$ patients underwent haemodialysis. We observed that early diagnosis and early intervention were probably responsible for good survival rate.

\section{Limitation}

The study is done in a limited number of patients. Results may vary when done in a large number of subjects.

\section{References}

1. Brady HR, Brenner BM. Acute kidney injury. Harrison's principles of internal medicine. Vol. 2. 16th edition. New York: McGraw - Hill : 2005.

2. Thadani R, Pascual M, Bonvette VB. Acute kidney injury. The New England Journal of Medicine 2006 ; 30 : 1448 1451.

3. Mindell JA, Chertow GM. A practical approach to acute kidney injury $2001 ; 81$ : $731-747$.

4. Hou SH, Broc ME. Hospital acquired renal indifficiency. A prospective study. American journal of medicine $2003 ; 74$ : $243-248$.

5. Eknoyan G. Emergency of concept of acute kidney injury. American Journal of nephrology $2002 ; 22: 225$ - 230.

6. Groeneveld ABG, Lins L. Acute kidney injury in medical intensive care unit. Nephron $2000 ; 59: 602$ - 610 .

7. Tran DD, Spiegel DM, Rerl T. Age, chronic disease, Sepsis organ failure and mortality in a medical intensive care unit. Critical care medicine 1999; $18: 474$ 479.

8. Singhal AS, Salkar AR, Chaudhary A, Fuscy SM. Clinical profile of acute kidney injury. JAPI $2002 ; 50: 71$ - 73. 